\title{
The influence of microstructure deformation on the corrosion resistance of cold formed stainless steel
}

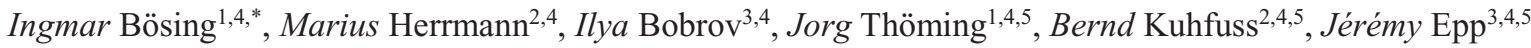 \\ and Michael Baune ${ }^{1,4}$ \\ ${ }^{1}$ UFT, Center for Environmental Research and Sustainable Technology, Leobener Strasse 6, 28359 Bremen, Germany \\ ${ }^{2}$ bime, Bremen Institute for Mechanical Engineering, Badgasteiner Str. 1, 28359 Bremen, Germany \\ ${ }^{3}$ Leibniz Institute for Materials Engineering IWT, Badgasteiner Str. 3, 28359 Bremen, Germany \\ ${ }^{4}$ University of Bremen \\ ${ }^{5}$ MAPEX Center for Materials and Processing
}

\begin{abstract}
Rotary swaging is an incremental cold forming process to produce axisymmetric workpieces from rods and tubes. The process also induces changes of the microstructure of the material depending on the process parameters. This in turn influences the mechanical properties like hardness as well as the electrochemical properties. As a result of changed electrochemical properties, the passivity of the material and thus the corrosion behavior changes. In order to investigate the influence of rotary swaging on the corrosion behavior of the stainless steel AISI304, deformed micro parts are electrochemically analyzed. The measurements reveal a dependency of corrosion rate and impedance on both feed velocity and final diameter of the rotary swaging process. A higher feed velocity decreases the corrosion rate and increases the impedance indicating a better resistance against corrosion as a side effect of rotary swaging.

Keywords: Cold forming, Stainless steel, Corrosion
\end{abstract}

\section{Introduction}

Rotary swaging is an incremental cold forming process to produce axisymmetric workpieces from rods and tubes. In the macro-range it has an important field of application in the automotive industry for example to produce axes, steering spindles and gear shafts [1]. It is also suitable for micro manufacturing to produce micro parts [2]. During infeed rotary swaging the workpiece is axially fed into the swaging unit and the diameter is reduced incrementally by a radially oscillating motion of three tools [3]. The swaging unit is rotating and the base jaws with the cam are passing the cylinder roller and induces the simultaneously radially stroke of the tools (Figure 1). The process shows several advantages of the produced parts like undisturbed fiber flow as well as improved mechanical properties [1]. Due to cold working, the tensile strength as well as the hardness increases during the process. Furthermore, the formability and also the microstructure of the material is influenced. This influence on the material properties depends on the process parameters like deformation degree or feed velocity as shown for the material AISI 304 [4]. Processes like rotary swaging, which cause mechanical deformation also on the microscale, can induce a transformation of this austenitic stainless steel into martensite. This change of microstructure influences the mechanical behavior of the

\footnotetext{
* Corresponding author: ingmar.boesing $@$ uni-bremen.de
}

produced workpieces [4]. The lower the infeed velocity during rotary swaging the higher the hardness compared to the initial state [5]. Thus more martensite is generated during the forming with lower feeding velocity [6]. Furthermore, the microstructure is significantly influenced by the deformation degree insofar as a texture is generated, grain size becomes smaller and the elongated grains are formed in the longitudinal direction [7].

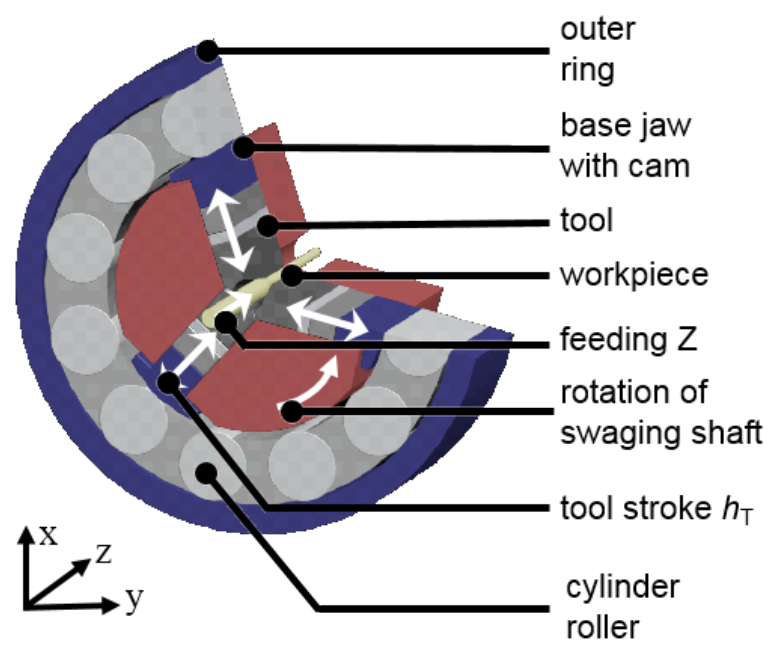

Fig. 1: Principle of infeed rotary swaging. 
The changes in microstructure might affect not only the mechanical properties but also the electrochemical properties such as corrosion and the formation of protective passive layers. Stainless steel shows the ability to spontaneously form a protective oxide layer on the material surface. This passive layer is just a few nanometers thick and protects the steel against corrosion [8].

The thickness, composition and stability - and thus the protective effect of the passive layer depend on the composition of the alloy (e.g. a high content of chromium leads to a more protective layer $[9,10])$, the environmental conditions and the microstructure of the steel [11].

The microstructure on different scales influences the formation of the passive layer and can accelerate or decelerate corrosion processes. It could be observed that a smaller grain size leads to a more stable passive layer in passivating environment [12]. But the higher amount of lattice defects associated with small grains can also lead to a faster dissolution under aggressive conditions like acidic media [13]. Not only the grain size but also the crystal structure can have an impact on the corrosion behavior. Martensite for example shows a higher electrochemical activity and thus a faster dissolution by corrosive reactions than austenitic phase [14].

Electrochemical measurements are a common and a well-known tool to study passivity and corrosion. Corrosion is an electrochemical phenomenon since the oxidative conversion of metals is accompanied by an electron transfer and thus a measurable current. The corrosion reactions can be forced by applying a potential between the investigated sample and a counter electrode. By measuring the flowing current during the reaction it is possible to compare different samples with respect to their resistance against corrosion. A lower anodic current indicates lower dissolution by either a more noble composition or a better passivation.

By rotary swaging the grain size of the material decreases while the martensite content in stainless steel increases $[5,7]$. Both phenomena influences the passivity of the material. A smaller grain size leads to a better passivation while a higher martensite content leads to a faster dissolution. By choosing the optimal process parameters it should be possible not just to get improved mechanical properties like a higher hardness but also a better passivation and resistance against corrosion.

In this paper it will be shown that the martensite content depends on the feed velocity while the grain size depends on the final diameter. The additional electrochemical measurements reveal the dependency of both material parameters and thus process parameters on the corrosion behavior.

\section{Experimental set up}

\subsection{Rotary swaging}

Rotary swaging experiments were conducted with annealed workpieces of material AISI 304 (X5CrNi1810). The workpieces were fed with a direct linear motion drive with different feed velocities of $v_{\mathrm{f}}=1 \mathrm{~mm} / \mathrm{s}$, $5 \mathrm{~mm} / \mathrm{s}, 7.5 \mathrm{~mm} / \mathrm{s}$ and $10 \mathrm{~mm} / \mathrm{s}$ into the swaging head. The stroke height of the tools $\left(h_{\mathrm{T}}=0.1 \mathrm{~mm}\right)$ and the stroke frequency $\left(f_{\mathrm{st}}=102 \mathrm{~Hz}\right)$ were kept constant. A lubricant (Shell Macron 01 F-2) was applied to all forming operations. The initial diameter of the workpieces was $d_{0}=1 \mathrm{~mm}$. Two different forming operations were carried out. Thus two tool sets of the material 1.2379 (X155CrVMo12) were used, one with a nominal diameter of $d_{\text {nom } 1}=0.75 \mathrm{~mm}$ and second with a nominal diameter of $d_{\text {nom } 2}=0.46 \mathrm{~mm}$. Both tool sets had the same settings with a tool angle $\alpha=10^{\circ}$ and a calibration length $l_{\text {cal }}=20 \mathrm{~mm}$ (Figure 2). Workpieces were deformed in one stage with the first tool set to a final diameter of $d_{1}=0.8 \mathrm{~mm}$. An additional set of workpieces were deformed in two stages first to $0.8 \mathrm{~mm}$ and finally to $d_{1}=0.5 \mathrm{~mm}$ with the second tool set. When removing the workpiece from the swaging unit, the tools were opened to avoid further impact on the specimen.

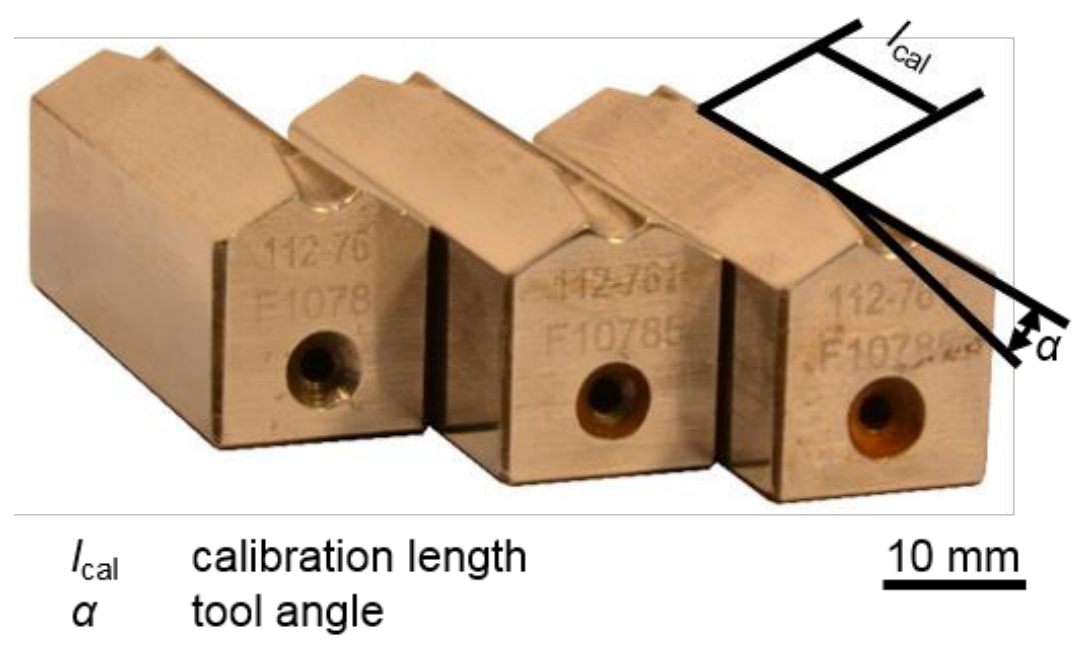

Fig. 2. Toolset for rotary swaging. 

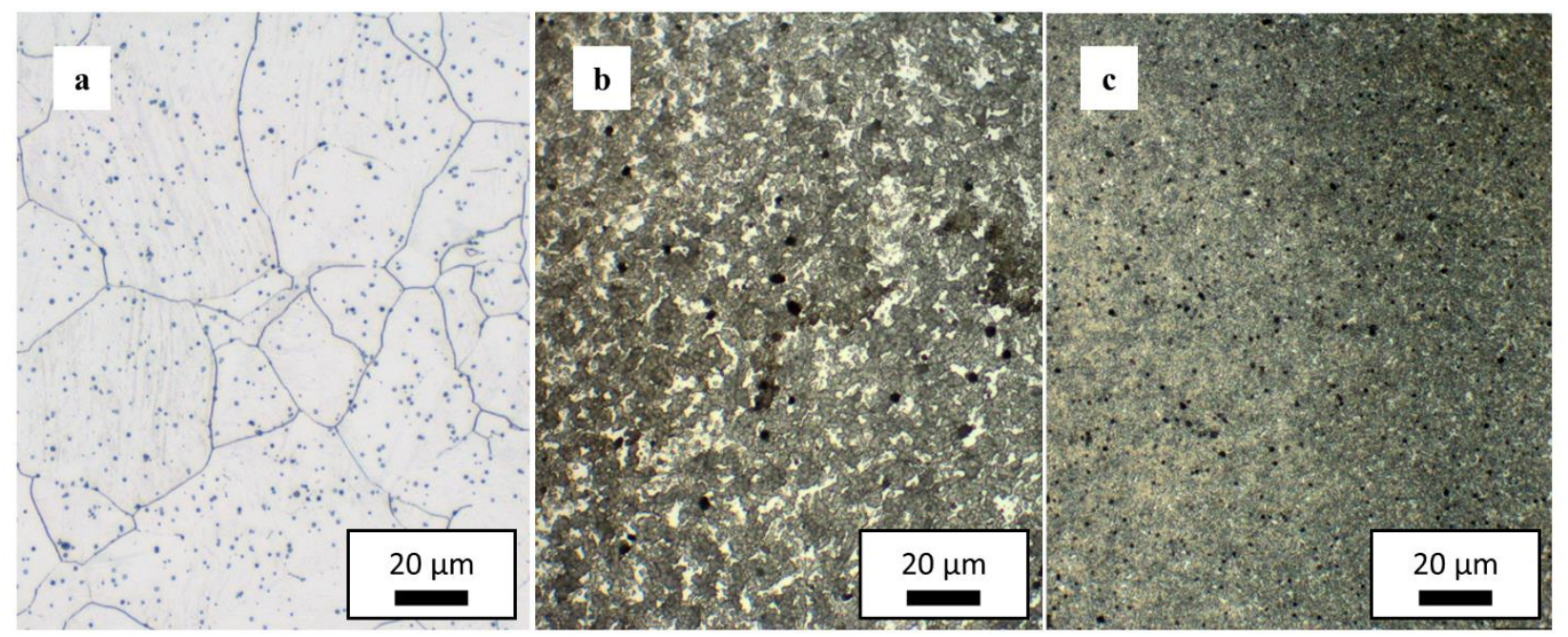

Fig. 3. Microstructure (cross-section polish) of (a) annealed material, (b) deformed material with final diameter $d_{1}=0.8 \mathrm{~mm}$ $(v=1.0 \mathrm{~mm} / \mathrm{s})$, (c) deformed material with final diameter $d_{1}=0.5 \mathrm{~mm}\left(v_{\mathrm{f}}=1.0 \mathrm{~mm}\right)$.

\subsection{XRD measurements}

For this study quantitative phase analysis [15] was performed using Cr-radiation $\left(K_{\alpha 1, \alpha 2}\right)$, produced by long fine focus tube $12 * 0.4$ (Panalytical). Diffracted radiation was detected by a position sensitive detector "Miostar 2" (Photron-X, Ottobrunn, Germany), equipped with vanadium filter. The measurements were performed on the outer surface of the wire, using a fox-mini-lens (IFG, Berlin, Germany), with incident beam diameter of $200 \mu \mathrm{m}$. All the diffraction profiles were obtained by varying $2 \theta$ from $60^{\circ}$ to $164^{\circ}$ with a resolution of $0.05^{\circ}$.

The collected XRD data was refined by Rietveld method [16] using the software TOPAS 4.2 (Bruker AXS, Karlsruhe, Germany). In this method, the whole measured pattern is refined with a calculated pattern, taking into account the instrumental contributions and the crystal structure of the present phases, including microstructural features like crystallite size and microstrains. The calculated criterion residuals weighted profile (weighted $\mathrm{R}$-factor; $R_{\mathrm{wp}}$ ) gives a reliable information about the fit quality. Thereby, the smallest $R_{w p}$ value represents the best refinement. It is calculated by:

$$
R_{\mathrm{wp}}=\sqrt{\frac{\sum U_{i}\left(Y_{i} o b s-Y_{i} c a l c\right)^{2}}{\sum\left(Y_{i} c a l c\right)^{2}}}
$$

In this equation $Y_{i}$ obs is the measured and $Y_{i}$ calc is the calculated intensity at each $2 \theta$ position $i$ [16].

\subsection{Electrochemical measurements}

All electrochemical measurements were carried out in a standard three electrode cell using a Metrohm Autolab potentiostat with the PGSTAT204 and the FRA32 modules. All experiments were performed at room temperature. The counter electrode was a platin electrode and the reference electrode was an $\mathrm{Ag} / \mathrm{AgCl}$ electrode, while the investigated material acts as the working electrode. The samples were embedded in a PTFE (Teflon) holder. All potentials in this paper are referred to the $\mathrm{Ag} / \mathrm{AgCl}$ electrode.

The electrochemical measurements, potentiodynamic polarization scans and electrochemical impedance spectroscopy, were done in phosphate buffered saline (PBS) containing $0.2 \mathrm{M} \mathrm{NaCl}+0.1 \mathrm{M}$ phosphate buffer solution [17] $(\mathrm{pH}=7.5)$. Before each measurement the working electrodes were wet grinded with $\mathrm{SiC}$ grinding paper up to 2000 grid, degreased in ethanol and cleaned in an ultrasonic bath containing deionized water.

The polarization scans were performed in PBS with a scan velocity of $1 \mathrm{mV} / \mathrm{s}$. Each polarization scan started from $-0.8 \mathrm{~V}$ and ended at $1.0 \mathrm{~V}$. Before every measurement the open circuit potential (OCP) was measured for 300 seconds.

The electrochemical impedance spectroscopy (EIS) measurements were performed at OCP which was measured for 1800 seconds. The EIS measurements were performed in the frequency range between $10^{5}$ and $0.1 \mathrm{~Hz}$ with an $\mathrm{AC}$ amplitude of $\pm 10 \mathrm{mV}_{\text {rms. }}$.

\section{Results and discussion}

\subsection{Microstructure analysis}

The microstructure of the annealed (initial state) material and two rotary swaged samples are shown in Figure 3. The annealed material is recognizable as austenitic steel with a grain size of $36.4 \mu \mathrm{m}$. By rotary swaging the grain size of the material was reduced significantly. The workpieces that were deformed in one stage to the final diameter $d_{1}=0.8 \mathrm{~mm}$ showed a grain size of $2.2 \mu \mathrm{m}$. With an additional deformation stage and a final diameter of $d_{1}=0.5 \mathrm{~mm}$ the grain size continued to be decreased down to $0.94 \mu \mathrm{m}$. 
Tab 1: Weighted dislocation density and refined martensite content in dependence of final diameter and feed velocity.

\begin{tabular}{lcc}
\hline Sample & $\begin{array}{c}\text { Average } \\
\text { dislocation } \\
\text { density, } \mathrm{cm}^{-2}\end{array}$ & $\begin{array}{c}\text { Martensite } \\
\text { content, } \\
\text { mass-\% }\end{array}$ \\
\hline As received & $1.17 \times 10^{9}$ & 0 \\
$d_{1}=0.8 \mathrm{~mm}$ & & \\
$v_{\mathrm{f}}=10 \mathrm{~mm} / \mathrm{s}$ & $1.81 \times 10^{10}$ & 21 \\
$v_{\mathrm{f}}=7.5 \mathrm{~mm} / \mathrm{s}$ & $1.82 \times 10^{10}$ & 27 \\
$v_{\mathrm{f}}=5 \mathrm{~mm} / \mathrm{s}$ & $1.61 \times 10^{10}$ & 35 \\
$v_{\mathrm{f}}=1 \mathrm{~mm} / \mathrm{s}$ & $1.59 \times 10^{10}$ & 47 \\
& & \\
$d_{1}=0.5 \mathrm{~mm}$ & & 55 \\
$v_{\mathrm{f}}=5 \mathrm{~mm} / \mathrm{s}$ & $1.56 \times 10^{10}$ & 80 \\
$v_{\mathrm{f}}=1 \mathrm{~mm} / \mathrm{s}$ & $1.14 \times 10^{10}$ & \\
\hline
\end{tabular}

A dependency of the grain size and the feed velocity could not be observed. Other studies came to the same result [5].

\subsection{XRD Measurements}

XRD was used to study the phase transformations taking place during rotary swaging. Figure 4 shows the XRD patterns of the annealed and deformed samples. In these diagrams $\gamma$ represents peaks of the austenitic phase and $\alpha$ represents martensite peaks. The labels of each scan describes final diameter of the wire and the feed velocity used during rotary swaging of the investigated samples. Figure 3 illustrates the evolution of martensite peaks and corresponding evolution of austenite peaks depending on the process parameters. The increase of the $\alpha$-peak is correlated with the generation of deformation-induced martensite during the process. Moreover, a broadening of the diffraction peaks can be observed.

The values of $R_{\mathrm{wp}}$ for the refinements of studied samples were in range of 3.2 to 3.9 which correspond to a

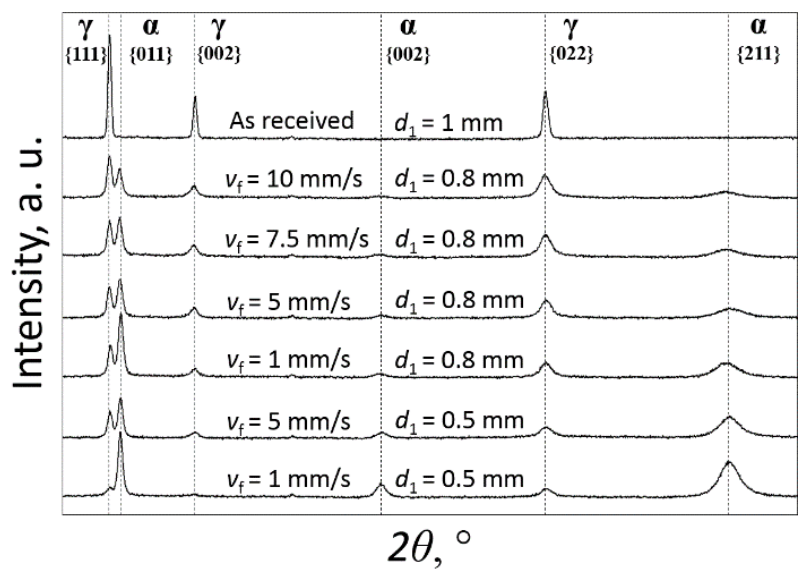

Fig. 4. : XRD-scans for rotary swaged wires by different feed velocities $v_{\mathrm{f}}$ and for initial wire (no RS). high fit quality. Phase composition was refined taking into account two existing phases: initial austenite (FCC, facecentered cubic) and deformation-induced martensite (BCC, body-centered cubic). Also the refinement was performed taking into account the texture with preferred orientation in $<011>$ direction, resulting from rotary swaging process. The degree of preferred orientation correction was refined by March-Dollase approach. The precision of the quantitative analysis of phase contents is estimated to be around \pm 5 mass- $\%$ in the present case. Microstructural parameters, such as microstrain $\left(e_{0}\right)$ and volume weighted crystalline block size $(D)$, also obtained by this refinement were used to calculate the dislocation density by:

$$
\rho=\sqrt{\frac{3 k \times\left(e_{0}\right)^{2}}{(D)^{2} \times 2.48 \times 10^{-21}}}
$$

with $k$ a structure depending factor, which takes values (calculated) of 16.1 for FCC materials and 14.4 for BCC materials [18]. The dislocation density was calculated for each of both existing phases. The average was calculated taking into account the determined respective phase contents. The results of these evaluations are shown in Table 1.

It shows, that dislocation density values for initial state were an order of magnitude smaller than for the wires after rotary swaging. The dislocation density values for samples subjected the rotary swaging with varied process parameters were comparable, but there seems to be no dependency on the process parameters and it has to be kept in mind that the measurements were performed on the outer surface and therefore, differences along the radius might take place. On the other hand, the process parameters had a significant influence on the martensite content. An increasing feed velocity led to a decreasing formation of martensite, while a higher diameter reduction increased the amount of martensite.

\subsection{Electrochemical measurements}

\subsubsection{Corrosion rate}

To determine the corrosion potential and the corrosion current density of the deformed samples and the initial state material polarization scans in PBS solution were performed. During the polarization scan a potential between the sample and the counter electrode was increased using a scan velocity of $1 \mathrm{mV} / \mathrm{s}$ and the current between the sample and the counter electrode was measured. The reference electrode served as a potential reference during the measurement (for more detailed description of the reference electrode the reader is referred to [19]). The applied potential caused corrosion on the surface of the workpiece and the measured current was directly linked to the converted mass via Faraday's law. So a high anodic current in areas of dissolution reactions (e.g $\mathrm{Fe} \rightarrow \mathrm{Fe}^{2+}$ ) indicates a fast corrosion process. Thus a 


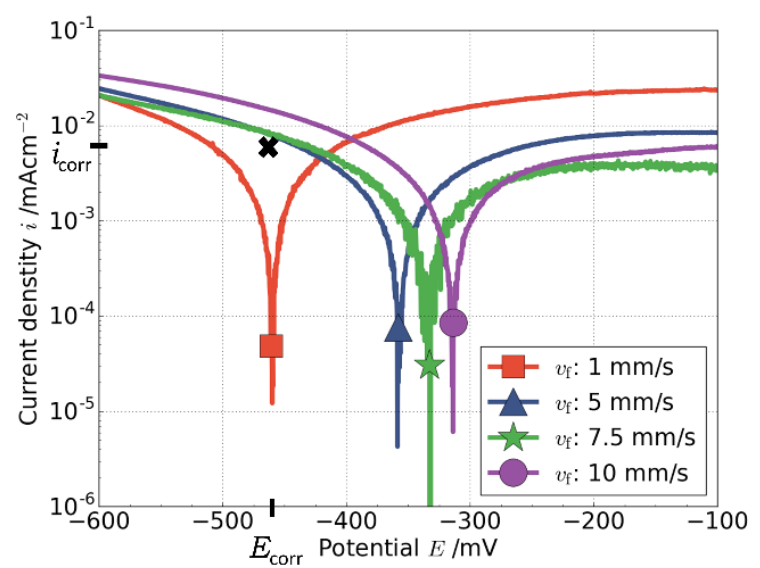

Fig. 5. Polarization scan in PBS. Final diameter $d_{1}=0.8$; variable feed velocity; scan velocity $1 \mathrm{mV} / \mathrm{s}$; all potentials referred to $\mathrm{Ag} / \mathrm{AgCl}$ electrode; the corrosion current density $i_{\text {corr }}$ and the corrosion potential $E_{\text {corr }}$ of sample $v_{\mathrm{f}}=1 \mathrm{~mm} / \mathrm{s}$ are shown as an example.

low corrosion current density $i_{\text {corr }}$ and high corrosion potential $E_{\text {corr }}$ indicate good corrosion resistance.

The aim of the polarization scans was to uncover a correlation between the process parameters feed velocity and final diameter and the electrochemical values corrosion potential and corrosion current density. In addition, the corrosion rate, which describes the dissolution by corrosion, can be calculated from the polarization scans.

Figure 5 shows the polarization scans of the deformed material with $d_{1}=0.8 \mathrm{~mm}$. The absolute value of the current density $|i|$ is plotted against the potential. At the beginning of the measurements a cathodic current related to the reduction of oxygen can be seen. While shifting to higher (less negative) potentials the cathodic current decreases. At the corrosion potential $E_{\text {corr }}$ the cathodic current is equal to the anodic current and the total current is zero. For the determination of the corrosion current density the linear courses of the anodic and cathodic currents are extended and the intersection of both lines indicates the value of the corrosion current (Tafel plot). At higher potentials the anodic current, which is related to the oxidation of the material, increases.

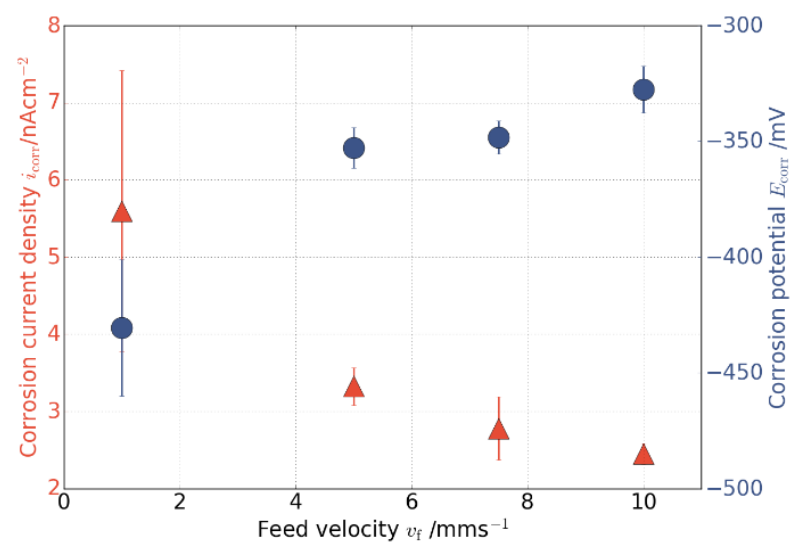

Fig. 6. Dependency of corrosion current density $i_{\text {corr }}$ and corrosion potential $E_{\text {corr }}$ from feed velocity for: final diameter $d_{1}=0.8 \mathrm{~mm}$.

The lowest corrosion potential and highest corrosion current density is assigned to the sample with the lowest feed velocity $\left(v_{\mathrm{f}}=1 \mathrm{~mm} / \mathrm{s}\right)$ during the forming process.

With increasing feed velocity the corrosion potential increases while the corrosion current density decreases (Table 2). Both of these characteristics indicate higher corrosion resistance.

Along with an increasing feed velocity the martensite content declines. It is known that martensite shows higher electrochemical activity than austenite $[14,20]$. This explains the lower corrosion current density and the higher corrosion potential with increasing feed velocity, which is obvious when corrosion current density and corrosion potential are plotted against feed velocity. Figure 6 shows this for a final diameter of $0.8 \mathrm{~mm}$, but the same trends were found for a final diameter of $0.5 \mathrm{~mm}$ (not plotted).

While $E_{\text {corr }}$ and $i_{\text {corr }}$ are clearly a function of feed velocity $v_{\mathrm{f}}$ the dependence on the final diameter is not that clear. The smaller final diameter (due to a second deformation step) yields a higher martensite content and a smaller grain size compared to the samples with larger final diameter and the untreated material. On the one hand a higher martensite content leads to a higher

Table 2. Corrosion potential and corrosion current density obtained by potentiodynamic polarization scans in PBS.

\begin{tabular}{|c|c|c|c|c|}
\hline Sample & & $\begin{array}{l}\text { Corrosion Potential } \\
E_{\text {corr }} / \mathrm{mV}\end{array}$ & $\begin{array}{l}\text { Corrosion current density } \\
i_{\text {corr }} / \mathrm{nAcm}^{-2}\end{array}$ & $\begin{array}{l}\text { Corrosion rate } \\
C R / \mu \mathrm{ma}^{-1}\end{array}$ \\
\hline \multirow{4}{*}{$d=0.8 \mathrm{~mm}$} & $v_{\mathrm{f}}=10 \mathrm{~mm} / \mathrm{s}$ & -327.7 & 2.45 & 2.56 \\
\hline & $v_{\mathrm{f}}=7.5 \mathrm{~mm} / \mathrm{s}$ & -384.8 & 2.78 & 2.90 \\
\hline & $v_{\mathrm{f}}=5 \mathrm{~mm} / \mathrm{s}$ & -352.9 & 3.32 & 3.47 \\
\hline & $v_{\mathrm{f}}=1 \mathrm{~mm} / \mathrm{s}$ & -443.9 & 5.59 & 5.84 \\
\hline \multirow[t]{3}{*}{$d=0.5 \mathrm{~mm}$} & $v_{\mathrm{f}}=10 \mathrm{~mm} / \mathrm{s}$ & -343.5 & 2.20 & 2.30 \\
\hline & $v_{\mathrm{f}}=5 \mathrm{~mm} / \mathrm{s}$ & -451.4 & 3.15 & 3.29 \\
\hline & $v_{\mathrm{f}}=1 \mathrm{~mm} / \mathrm{s}$ & -475.1 & 9.40 & 9.82 \\
\hline As received & & -390.5 & 4.38 & 4.57 \\
\hline
\end{tabular}


electrochemical activity while on the other hand a smaller grain size leads to a better passivation of stainless steel.

So the differences between samples treated with the same feed velocity but different final diameter shrink with increasing feed velocity (Table 2). Comparing sample $d_{1}=0.8 \mathrm{~mm}$ and $v_{\mathrm{f}}=10.0 \mathrm{~mm} / \mathrm{s}$ with sample $d_{1}=0.5 \mathrm{~mm}$ and $v_{\mathrm{f}}=10.0 \mathrm{~mm} / \mathrm{s}$ both corrosion current densities are nearly the same $(2.45 \mathrm{nA}$ and $2.20 \mathrm{nA}$ respectively). The smaller grain size of two times deformed samples $\left(d_{1}=0.5 \mathrm{~mm}\right)$ seems to compensates the higher martensite content resulting in nearly the same corrosion behavior.

The corrosion rate is the material loss per time due to corrosion under the given conditions. It is a function of the corrosion current density and is given in micrometers per year.

The corrosion rate $C R$ is given by

$$
C R=\frac{i_{\text {corr }} M t}{n F}
$$

with the corrosion current density $i_{\text {corr }}$, the molar mass $M$ the time $t$, the charge number $n$ which indicates the number of electrons exchanged in the dissolution reaction and $F$ is the Faraday constant. The quotient $M / n$ is sometimes referred to as equivalent weight. The different values of the corrosion rate are summarized in Table 2 . According to Equation $3 i_{\text {corr }}$ is the only variable parameter so the corrosion rate correlates linear with the corrosion current density. Due to the significant smaller grain size compared to the initial state material the deformed samples with low martensite content $\left(v_{\mathrm{f}}=5 \mathrm{~mm} / \mathrm{s}-v_{\mathrm{f}}=10 \mathrm{~mm} / \mathrm{s}\right)$ show even a lower corrosion rate than the pure austenitic as received material.

The polarization scans reveal a dependency of the corrosion potential and the corrosion rate on the feed velocity (Figure 5). The corrosion potential increases with feed velocity $v_{\mathrm{f}}$, while the corrosion rate decreases with $v_{\mathrm{f}}$. So an increasing feed velocity improves the corrosion behavior.

\subsubsection{Corrosion resistance}

To underline the findings of the polarization scans and to investigate the corrosion resistance of the samples electrochemical impedance spectroscopy (EIS) measurements were performed in PBS solution. During the EIS measurements an AC voltage with decreasing frequency $(10 \mathrm{kHz}-0.1 \mathrm{~Hz})$ was applied between the sample and a counter electrode. While the measurement the AC resistance - the impedance - as well as the phase shift was measured. The impedance of the electrochemical system can be interpreted as a resistance against corrosion.

In Figure 7 the real part of the impedance ( $\left.Z^{\prime}\right)$ is plotted against the imaginary part of the impedance (-Z''). With decreasing frequency the absolute impedance increases. Figure 6 reveals the same relationship that was already observed in the polarization scans.

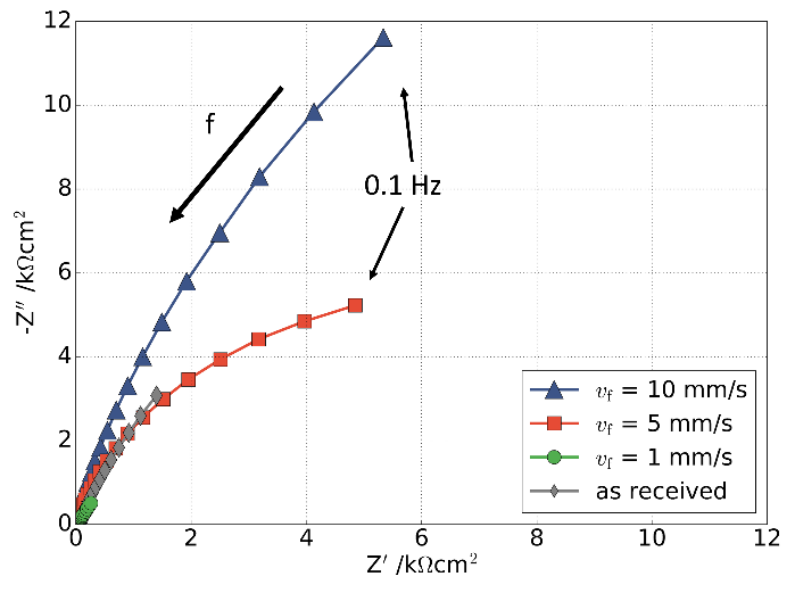

Fig. 7. Nyquist plot of the rotary swaged and initial material recorded at OCP in PBS solution.

The impedance, so the resistance against corrosion, increases with increasing feed velocity and thus decreasing martensite content.

The differences between the impedance values for one and two deformation steps also shrink with increasing feed velocity. At a feed velocity of $v_{\mathrm{f}}=10 \mathrm{~mm} / \mathrm{s}$ the impedance values of both samples are nearly the same. The higher martensite content appears to compensate for the smaller grain size and nearly the same corrosion behavior can be observed. It can also be seen that it is possible to increase the impedance of the deformed material compared to the initial material. The smaller grain size improves the corrosion resistance $\left(v_{\mathrm{f}}=10 \mathrm{~mm} / \mathrm{s}\right.$ and $v_{\mathrm{f}}=5 \mathrm{~mm} / \mathrm{s}$ compared to as received) but with increasing martensite content $\left(v_{\mathrm{f}}=1 \mathrm{~mm} / \mathrm{s}\right)$ the impedance gets smaller compared to the initial material (Table 3).

The EIS measurements confirm the same relationship like the polarization scans between corrosion resistance and the feed velocity. A higher feed velocity leads to a better passivation and a better corrosion resistance visible through a high impedance (Figure 7) and a low corrosion current density (Figure 5).

Table 3. Impedance values measured in PBS for one $\left(d_{1}=0.8 \mathrm{~mm}\right)$ and two $\left(d_{1}=0.5 \mathrm{~mm}\right)$ deformation steps.

\begin{tabular}{llr} 
Sample & \multicolumn{2}{c}{$\begin{array}{c}\text { Impedance } \\
Z / \mathrm{M} \Omega\end{array}$} \\
\hline \multirow{2}{*}{$d_{1}=0.8 \mathrm{~mm}$} & $v_{\mathrm{f}}=10 \mathrm{~mm} / \mathrm{s}$ & 5.78 \\
& $v_{\mathrm{f}}=5 \mathrm{~mm} / \mathrm{s}$ & 5.31 \\
& $v_{\mathrm{f}}=1 \mathrm{~mm} / \mathrm{s}$ & 4.17 \\
& & 5.90 \\
$d_{1}=0.5 \mathrm{~mm}$ & $v_{\mathrm{f}}=10 \mathrm{~mm} / \mathrm{s}$ & 4.46 \\
& $v_{\mathrm{f}}=5 \mathrm{~mm} / \mathrm{s}$ & 2.01
\end{tabular}

As received 4.06 


\section{Conclusion}

In this study workpieces deformed by rotary swaging were investigated by analyzing the microstructure and the electrochemical properties. The grain size of AISI 304 decreases with every deformation stage and straininduced martensite is built during the process. It could be shown that the martensite content increases with increasing deformation while an increasing feed velocity can decrease the amount of formed martensite. On the other hand, no significant impact of the feed velocity on the grain size nor the dislocation density could be observed.

The martensite content is directly linked to the corrosion behavior. A high martensite content leads to faster dissolution measurable by a higher corrosion current density and corrosion rate as well as by a low impedance. With increasing feed velocity the corrosion current density (and thus the corrosion rate) decrease while the impedance of the workpiece increase, which can be attributed to the decreasing amount of built martensite.

The grain size also has a significant effect on the corrosion behavior namely a smaller grain size leading to a lower corrosion current density and a higher impedance. Both indicates a better resistance against corrosion.

By choosing a high feed velocity it is therefore possible to achieve a better protection against corrosion compared to the initial material, even despite a higher martensite content, due to the significant reduction of the grain size. These effects were visible in a lower corrosion rate and a higher impedance of the deformed material with feed velocities from $v_{\mathrm{f}}=5 \mathrm{~mm} / \mathrm{s}$ to $v_{\mathrm{f}}=10 \mathrm{~mm} / \mathrm{s}$.

The results confirmed that it is not just possible to influence the mechanical and geometrical properties of stainless steel AISI 304 by rotary swaging but also the resulting electrochemical properties. The choice of the right process parameters can lead to an increased hardness as well as to an increased corrosion resistance.

Besides martensite content and grain size other factors can also influence the corrosion behavior or the passivation. For example microstructural properties like texture [21], grain size distribution [22] and coincident site lattice boundaries (by suppression of sensitization through chromium depletion) $[23,24]$ can play an important role. Further investigations on the influence of rotary swaging on these microstructure properties and thus the properties of the passive layer also seem to be very promising and will be in focus of future investigations.

Financial support of subproject D03 "Electrochemical High Throughput Characterization of Metallic Micro Samples" and D01 "Qualification of material conditions with mechanical and physical measuring methods" of the Collaborative Research Center SFB 1232 "Farbige Zustände" by the German Research Foundation (DFG) is gratefully acknowledged.

The authors would also like to thank the German Research Foundation for funding this work within the sub-project "Control of component properties in rotary swaging process" of the priority program SPP 2013 "The utilization of residual stresses induced by metal forming".

Further acknowledgements to Georg Pesch for fruitful scientific discussion and proof reading of this paper.

\section{References}

1. E. Rauschnabel and V. Schmidt, J. Mater. Process. Technol., vol. 35, no. 3-4, pp. 371-383 (1992)

2. B. Kuhfuss, E. Moumi, and V. Piwek, Microsyst. Technol., vol. 14, no. 12, pp. 1995-2000 (2008)

3. B. Kuhfuss; E. Moumi: Incremental Forming. In: Micro Metal Forming, Hrsg. F. Vollertsen, Springer Verlag, ISBN-13: 9783642309151 (2013)

4. S. K. Ghosh, P. Mallick, and P. P. Chattopadhyay, J. Iron Steel Res. Int., vol. 19, no. 4, pp. 63-68 (2012)

5. B. Köhler, B. Clausen, H.-W. Zoch, 8. Kolloquium Mikroproduktion, (BIAS Verlag, 9198, 2017)

6. E. Moumi; B. Kuhfuss, Properties Of Alloy 204 Micro Parts Processed by Rotary Swaging, nanoMan (2014)

7. S. J. Lim, H. J. Choi, and C. H. Lee, J. Mater. Process. Technol., vol. 209, no. 1, pp. 283-288 (2009)

8. J. Kruger, Int. Mater. Rev., vol. 33, no. 1, pp. 113130 (1988)

9. K. Sieradzki and R. C. Newman, J. Electrochem. Soc., vol. 133, no. 9, pp. 1979-1980 (1986)

10. D. E. Williams, R. C. Newman, Q. Song, and R. G. Kelly, Nature, vol. 350, no. 6315, pp. 216-219 (1991)

11. P. Schmuki, J. Solid State Electrochem., vol. 6, no. 3, pp. 145-164 (2002)

12. K. D. Ralston and N. Birbilis, Corrosion, vol. 66, no. 7, pp. 1-4 (2010)

13. L. Liu, Y. Li, and F. Wang, J. Mater. Sci. Technol., vol. 26, no. 1, pp. 1-14 (2010)

14. C. C. Xu and G. Hu, Anti-Corrosion Methods Mater., vol. 51, no. 6, pp. 381-388 (2004)

15. J. Epp, XRD methods for materials Characterization in Mat. Charact. Using Nondestr. Evaluation (NDE) Meth., Woodhead publishing pp. 81-124 (2016)

16. G. Will, Powder diffraction: The rietveld method and the two stage method to determine and refine crystal structures from powder diffraction data (Springer Science \& Buisness Media, 2006)

17. I. Bösing, J. Thöming, and M. Baune, Electrolyte Composition for Distinguishing Corrosion Mechanisms in Steel Alloy Screening, vol. 2017, 2017

18. G. K. Williamson and R. E. Smallman, Philos. Mag., vol. 1, no. 1, pp. 34-46 (1956)

19. A. Bard and L. Faulkner, Electrochemical Methods: Fundamentals and Applications (New York: Wiley, 2001)

20. S. Sunada, N. Nakamura, H. Kawase, H. Notoya, S. Sanuki, and K. Arai, Nippon Kinzoku 
Gakkaishi/Journal Japan Inst. Met., vol. 55, no. 6, pp. 660-666 (1991)

21. B. R. Kumar, R. Singh, B. Mahato, P. K. De, N. R. Bandyopadhyay, and D. K. Bhattacharya, Mater. Charact., vol. 54, no. 2, pp. 141-147 (2005)

22. S. Gollapudi, Corros. Sci., vol. 62, pp. 90-94, 2012

23. H. Y. Bi, H. Kokawa, Z. J. Wang, M. Shimada, and Y. S. Sato, Scr. Mater., vol. 49, no. 3, pp. 219-223, 2003

24. M. Shimada, H. Kokawa, Z. J. Wang, Y. S. Sato, and I. Karibe, Acta Mater., vol. 50, no. 9, pp. 2331-2341 (2002) 